\title{
Performance Evaluation of a Micro-Steam Turbine Powered Electric Generator under Changeable Bed and Drive Mechanisms
}

\author{
Rasheed Aina*, Buliaminu Kareem, Adegoke Ayodeji, Rasheed Shittu \\ Department of Industrial \& Production Engineering, The Federal University of Technology, Akure, Nigeria \\ Email: ^Rasheed.olalekan18@gmail.com, bkareem@futa.edu.ng
}

How to cite this paper: Aina, R., Kareem, B., Ayodeji, A. and Shittu, R. (2022) Performance Evaluation of a Micro-Steam Turbine Powered Electric Generator under Changeable Bed and Drive Mechanisms. Journal of Power and Energy Engineering, 10, 29-36. https://doi.org/10.4236/jpee.2022.102003

Received: November 27, 2021

Accepted: February 25, 2022

Published: February 28, 2022

Copyright $\odot 2022$ by author(s) and Scientific Research Publishing Inc. This work is licensed under the Creative Commons Attribution International License (CC BY 4.0).

http://creativecommons.org/licenses/by/4.0/

\begin{abstract}
Machines are growth engines of the economy; each sector of the economy achieves its demand by the use of the machine. They are installed in various establishments for the purpose of using them to perform certain functions or others. However, as a result of the kind of forces, dynamic and static loads, they transmitted to their adjoining surroundings when used, they are often mounted on supporting structures, foundations or a combination of them to achieve adequate or appropriate safe operation and stability. When a machine is operating, it is subjected to several time-varying forces and as a result of which it tends to exhibit vibrations. In such a situation or process, a certain quantity of this force is transmitted to the foundation, which could undermine the life of the foundation and also affect its performance and the operation of any other machines on the same foundation. Hence, it makes sense to minimize this force transmission. This research aimed at developing an adjustable steelframed structure for supporting the major components of a $5.0 \mathrm{~kW}$ microsteam power unit (steam, turbine and alternator) and evaluating the performance of the unit with or without the vibration isolator when they are axially connected with flexible flange coupling or transversely connected with sets of belts and pulleys, in succession, respectively. The results showed that reduction in the force transmitted to the supporting structure occurred when the vibration produced by the unit is isolated from its base by the use of a vibration isolator, maximum reduction of $99.95 \%$ achieved when axially coupled and $99.91 \%$ when transversely connected with belt and pulley system. The results also showed that better performance would be attained when the steam turbine is axially coupled to the alternator than when connected with belt and pulley; The maximum voltage of $52 \mathrm{~V}$ and speed of $1000 \mathrm{rpm}$ at $77 \mathrm{~dB}$ sound level attained with coupling connection, and voltage of $20 \mathrm{~V}$ and speed of $752 \mathrm{rpm}$ at $75 \mathrm{~dB}$ with belt and pulley connection.
\end{abstract}




\section{Keywords}

Vibration Isolator, Axially Coupled, Transverse Couple, Adjustable Bed

\section{Introduction}

Machines are the growth engines of the economy. Each sector of the economy fulfils its demand by the use of the machine. Machines play a vital role in the economy. The use of the machine since the past few decades has been increasing rapidly and it is not only in industrial/rural areas but also in small isolated/rural areas. When a machine is operating, it is subjected to several time-varying forces and as a result of which it tends to exhibit vibrations (period and aperiodic oscillations) [1] [2] [3]. In the process, a certain quantity of this force is transmitted to the foundation-which could undermine the life of the foundation and also affect the operation of any other machines on the same foundation [4]. Hence, it makes sense to minimize this force transmission. The demand for electrical energy has been on the increase ever since when man achieved the breakthrough and continual advancement in technology, series of energy-consuming appliances have been produced to meet the increasing standard of living of the populace/consumers [5]. In contrast, not all the units of energy generated in every kind of power plant are available for transmission and onward distribution; some are wasted by the energy-generating plants, which could not easily be accounted for. According to Chattopadhyay (2004), about $10 \%$ of the energy generated in power industries cannot be accounted for and is viewed as unaccountable energy losses. One of the factors responsible for this is the unwanted vibration of the rotating component of the unit. Vibration could cause machinery to consume excessive power, damage product quality and ultimately knock it out of service and halt plant production [3] [4]. There have been some effective attempts at reducing the vibration intensity in some of the rotating machines, like a steam turbine, but the interventions have not yet optimal results. The scope of the research would be limited to the development of an adjustable steel-frame structure, as a supporting structure for mounting a 5.0 $\mathrm{kW} \cdot \mathrm{h}$ micro-steam turbine-alternator, prior to its mounting on a block-type concrete foundation [6]. The steel-frame supporting structure was made adjustable to facilitate adjustment of the major components of the micro-steam thermal unit in cases when they were axially coupled together with flexible flange coupling or transversely connected together with sets of belts and pulleys. The vibration investigation and analysis would be of a single degree of freedom type (1 d.o.f) as it would be limited to the isolation of the vibration transmitted by the machine (combined steam generator and alternator) to the developed adjustable steelframed supporting bed only (vibration transmitted to the concrete box-type foundation would not be considered) [7] [8]. Due to the fact of the reduction of the force transmitted to the supporting structure can be monitored/investigated at varied damping factors and frequency ratios. The selection of the vibration isolator (pads) for cush- 
ioning the vibration effect would be done based on the values of the damping factor and frequency ratio that gives the least force transmissibility factor [9].

\section{Materials and Methods}

\subsection{Overview of Properties of Existing Isolating Materials}

Isolators are made from a wide variety of resilient media having diverse characteristics. Each type of isolator has characteristic properties tailored to certain specialized applications. For the purpose of making the best use of available isolators, designer needs to: understand the basic properties of each type, be familiar with the requirements for isolators for various types of equipment, and keep in mind that not all isolators can be manufactured out of any material [10]. They are usually specified by their static deflection, that is, how much they deflect when the weight of the machine is placed on them Vibro-isolators used for reducing vibration of machinery mounted on supporting structures or foundation include the cork, felt, rubber, and metal springs. In practice, isolators are not massless as assumed in classical analysis [11].

The choice of method to reduce transfer of vibration between a system and surrounding varied depending on the applications, properties of isolators, excitation frequency and condition of the machine environment. Table 1 provides a guide to the isolator type and alongside with the static deflection over given values of operating speed and isolation efficiency. While isolate a system the procedure for using this table involves reading the minimum static deflection against the system disturbing (excitation) frequency and required isolation efficiency. In this study, since the estimated isolation efficiency is $R \geq 80 \%$ at $r=4$, and disturbing speed of $1500 \mathrm{rpm}$, based on this, the choice of isolator that would be considered is rubber mounting [12].

Detailing below are the properties of the steam turbine, alternator and the isolator Mass of machine:

$\begin{array}{ll}\text { Turbine }\left(m_{t}\right): & 10.0 \mathrm{~kg} \\ \text { Alternator }\left(m_{a l}\right): & 15.0 \mathrm{~kg} \\ \text { Number of buckets }\left(n_{b}\right): & 15 \\ \text { Total mass of the buckets } & 1.0 \mathrm{~kg} \\ \text { Steam consumption }\left(m_{s l}\right): & 68 \mathrm{~kg} / \mathrm{hr}\end{array}$

Table 1 . The stiffness values of typical isolators.

\begin{tabular}{ccc}
\hline Material & Deflection $(\mathrm{mm})$ & Frequency $(\mathrm{Hz})$ \\
\hline Cork or felt & $0.1-0.5$ & $50-25$ \\
Rubber & $0.1-10$ & $50-5$ \\
Metal springs & $5-50$ & $5-1$ \\
\hline
\end{tabular}

Source: vehicle refinement controlling noise and operation in road vehicles, Harrison (2004). 
Balance quality factor $(Q)$ G2.5

Dimensions of the isolator (each)

Adjustable bed dimensions: Length of $100 \mathrm{~mm}$, breadth or width $50 \mathrm{~mm}$ and height of $25 \mathrm{~mm}$

Unbalanced rotating mass $\left(m_{u}\right)$ :

Non-rotating mass $\left(M-m_{u}\right)$

$F_{e}$

Number of mounts $\left(n_{p}\right)$

Stiffness of the vibration isolator
$2.133 \mathrm{~kg}$

$23.9997 \mathrm{~kg}$

$87.71611 \mathrm{~N}$

4

$141.91 \mathrm{~N} / \mathrm{MM}$

\subsection{Experimental Procedure}

Experiment Data and Analysis

The experimental data obtained in the course of the experimentation are as detailed in Table 2 and Table 3 below. Table 2 shows the data recorded with the attached instrumentations when the two main components (steam turbine and alternator) test rig were connected transversely with belt and pulley system whilst Table 3 shows the experimental data when they are axially connected with flexible flange coupling. Figure 1 shows both axial and transverse assembly form of the system. The axial connection is with the aid of coupling while transverse is with bell and pulley [13] [14].

\section{Results and Discussions}

This study aimed at evaluating the contributory effect of vibration isolator on

Table 2. Experimental data obtained with the test rig connected together using belt and pulley system.

\begin{tabular}{ccccccccccc}
\hline & \multicolumn{3}{c}{ With test rig mounted on vibration isolator } & \multicolumn{4}{c}{ Test rig not mounted on vibration isolator } \\
\cline { 2 - 10 } & $S(\mathrm{~mm})$ & $\boldsymbol{V}(\mathrm{mm} / \mathrm{s})$ & $\boldsymbol{a}\left(\mathrm{mm} / \mathrm{s}^{2}\right)$ & $V(\mathrm{~V})$ & $\boldsymbol{N}(\mathrm{rpm})$ & $\boldsymbol{S}(\mathrm{mm})$ & $\boldsymbol{V}(\mathrm{mm} / \mathrm{s})$ & $\boldsymbol{a}\left(\mathrm{mm} / \mathrm{s}^{2}\right)$ & $V(\mathrm{~V})$ & $\boldsymbol{N}(\mathrm{rpm})$ \\
\hline 1 & 2.7 & 63.0 & 1.4 & 20.0 & 752 & 1.2 & 75 & 0.9 & 10.0 & 656 \\
2 & 1.7 & 47.0 & 1.1 & 5.0 & 549 & 1.0 & 55 & 0.6 & 8.0 & 599 \\
\hline
\end{tabular}

Table 3. Experimental data obtained with the test rig connected together using Flange coupling system.

\begin{tabular}{|c|c|c|c|c|c|c|c|c|c|c|}
\hline \multirow{2}{*}{$s / n$} & \multicolumn{5}{|c|}{ With test rig mounted on vibration isolator } & \multicolumn{5}{|c|}{ Test rig not mounted on vibration isolator } \\
\hline & $S(\mathrm{~mm})$ & $V(\mathrm{~mm} / \mathrm{s})$ & $a\left(\mathrm{~mm} / \mathrm{s}^{2}\right)$ & $V(\mathrm{~V})$ & $N(\mathrm{rpm})$ & $S(\mathrm{~mm})$ & $\operatorname{vel}(\mathrm{mm} / \mathrm{s})$ & $a\left(\mathrm{~mm} / \mathrm{s}^{2}\right)$ & $V(\mathrm{~V})$ & $N(\mathrm{rpm})$ \\
\hline 1 & 1.33 & 43.1 & 12.2 & 52 & 1000 & 1.175 & 43.4 & 12.37 & 52 & 1000 \\
\hline 2 & 1.192 & 43.3 & 17.7 & 52 & 1000 & 1.122 & 44.1 & 18.2 & 52 & 1000 \\
\hline Displacement & Vel. $(\mathrm{mm} / \mathrm{s})$ & Mmls Acc & Voltap & $8 \mathrm{pm}$ speed & Displacement & vel & acc & Volt & Speed & \\
\hline $940 / 3 / 2.7$ & 6.3 & 1.4 & 20.0 & 752 & 1.2 & 7.5 & 0.9 & $10 \mathrm{v}$ & 656 & \\
\hline 17 & 4.4 & 1.1 & 50 & 549 & 10 & 5.5 & 0.6 & & & \\
\hline 1.263 & 41.8 & 11.1 & 560 & 950 & 1.211 & 4.5 & & 53 & 1030 & \\
\hline 1.33 & 43.1 & 12.2 & 5.2 & 1000 & 1.175 & 43.4 & & 52 & 1000 & \\
\hline 1.193 & 43.3 & 17.7 & 5.2 & 1000 & 1.121 & 43.1 & & 52 & 1000 & \\
\hline
\end{tabular}




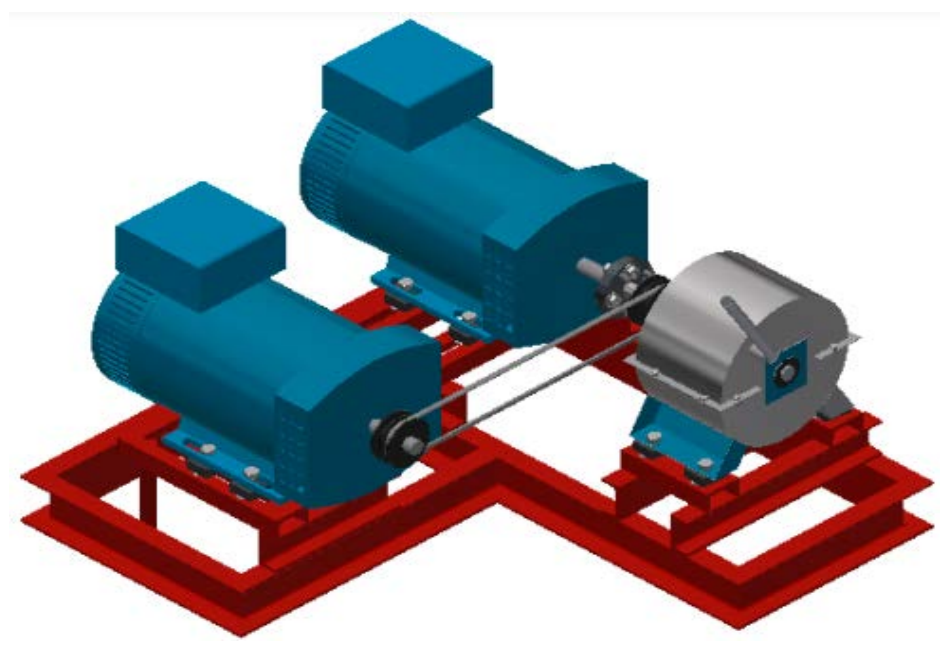

Figure 1. Axial and transverse assembly of a micro-steam turbine on changeable bed.

the performance of the major components of micro-steam thermal unit mounted on an adjustable steel framed bed before mounted on a concrete floor [1] [2].

This section presents the results and discussions of the analysis of the experimental data obtained in the course of the experimentations, when the steam turbine and alternator were axially connected with a flange coupling or transversely connected with sets of belt and pulley systems and when they were supported at their bases with vibration isolator before mounting on the developed adjustable steel framed bed and when mounted directly on the steel frame without the insertion of vibration isolator, in succession, respectively [3].

For the purpose of evaluating the effect of vibration isolator on the performance of the steam turbine-alternator unit, the parameters utilized for comparing the performance are: the ratios of the damped frequency to the undamped frequency of the test rig when with/without vibration isolators and vibration isolator reduction efficiency [4].

Table 4 presents results of the Performance of the test rig when mounted on the developed adjustable steel-framed bed with/without insertion of vibration isolator with respect to the ratio of the damped frequency to the undamped frequency and vibration reduction efficiency [5].

Tables 2-4 present a detail of comparison of the observed experimental when the combined steam-turbine-alternator was mounted on the developed adjustable bed as shown in Figure 1, with vibration isolator inserted and when not inserted between them and the bed.

From Table 4, it was observed that the resistance offered by the isolator when used to cushion, the effect of vibration of the machine against the supporting adjustable bed, is more than when the machine is directly mounted on the supporting bed [6] [7]. The resistance offered with the use of sets of belt and pulley systems as a power transmission is greater than when a flange coupling is used; the reason is that with the use of belt and pulley, both torsional and bending moments are experienced by the machine as the steam turbine shaft and alternator 
Table 4. Summary of the calculated results with reference to the experimental data obtained.

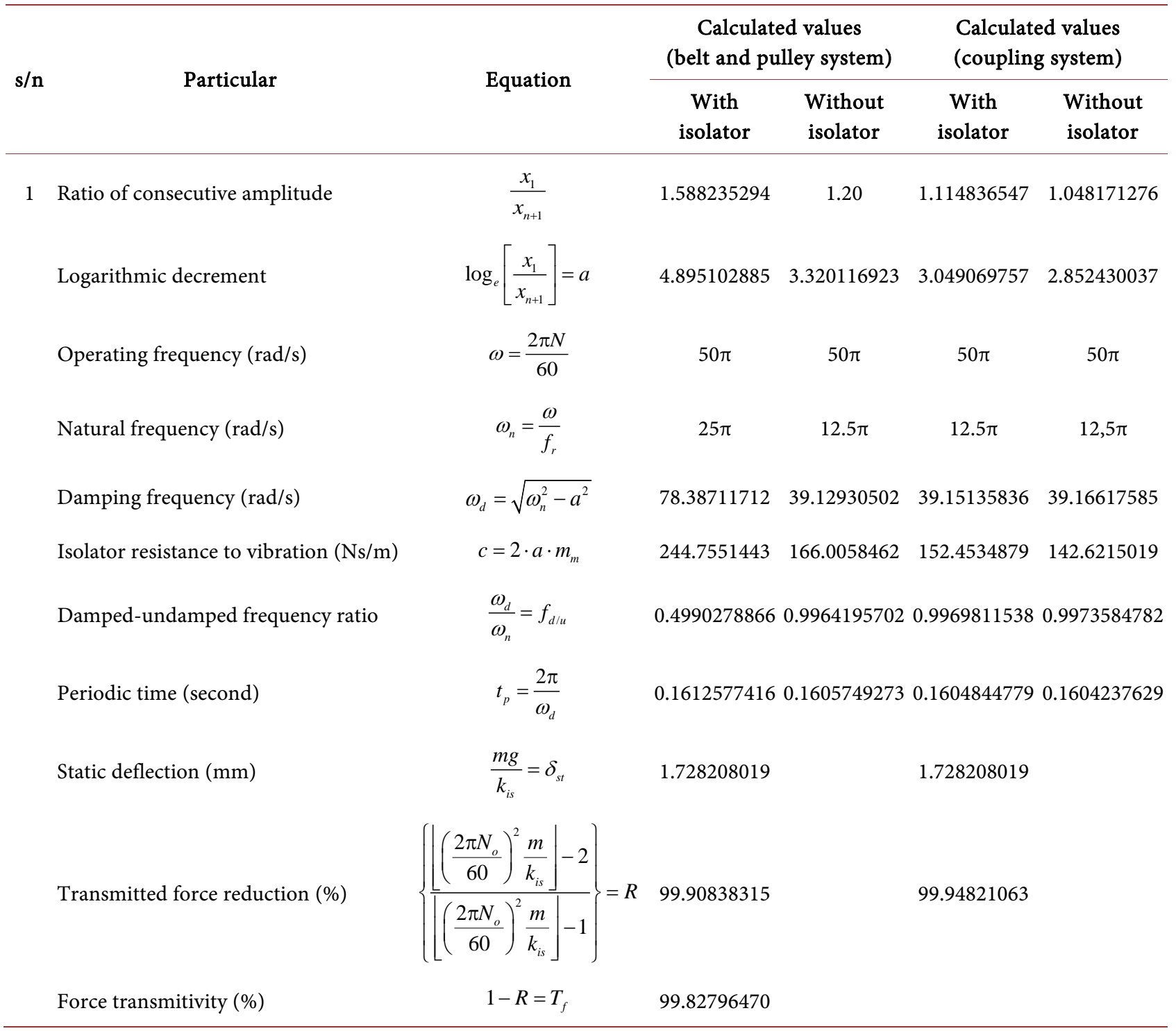

shaft are transversely positioned to each other, but when a flexible flange coupling is used as the power transmission system, only the two components of the micro power plant is subjected to only torsional moment.

The results also showed that the use of vibration isolator reduction the quantity of the force transmitted to the supporting bed is reduced, with the maximum reduction achieved when the unit was axially connected with coupling than when transversely connected with sets of belt and pulley systems [8].

However, maximum power was generated with the use of flange coupling than when the machine was connected with belt and pulley system; this could be attributed to the fact that: with the use of coupling the two components (steam turbine and alternator) worked same speed ratio of unity (1.0) or speed of $1500 \mathrm{rpm}$, hence little or no opposing force was offered by the alternator to the motion of the steam turbine, but with the use of belt and pulley system the speed ratio of 
turbine to alternator is 1:3 (or speed of $1500 \mathrm{rpm}$ to $4500 \mathrm{rpm}$ ) a value outside the range of e design property of the manufacturer design and working capacity of the alternator hence the opposing force offered by the alternator was higher than with coupling and this accounted for reduction in the power generated when belt and pulley was utilized as the power transmission system [9].

\section{Conclusions}

The primary objective of this study was the performance assessment of micro-steam turbine-alternator mounted on the developed adjustable steel-framed bed as shown in Figure 1 when their shafts were either axially connected together with flexible flange coupling or transversely with sets of belt and pulley power transmission. Also, the evaluation was done, in succession, when these components were isolated from the bed by the insertion of vibration isolator between their bases and developed bed and when they were mounted directly on the bed without the use of vibration isolator respectively. To achieve this aim, experimental data were obtained, with the aid of the attached instrumentations, when they were connected with coupling, or belt and pulley system and isolated from the developed bed with vibration isolator, and when connected with any of these two power transmission systems in succession and mounted directly on the developed bed without the use of vibration isolator respectively [10] [11]. The results showed that the performance of the components of the micro steam thermal unit is not only being influenced by the kinds of power transmission systems used to connect them together, but also whether the vibration produced by them is isolated/cushioned or transmitted directly to their supporting structures. Based on this, the following conclusions have been made from the experimental investigation:

1) Reduction in the force transmitted to the supporting bed was when the two components were isolated from their supporting structures with the insertion of a vibration isolator [12];

2) Better performance was achieved when the components were axially connected with coupling than transversely with sets of belt and pulley systems. The maximum voltage of $52 \mathrm{~V}$ and speed of $1000 \mathrm{rpm}$ at $77 \mathrm{~dB}$ sound level attained with coupling connection, and voltage of $20 \mathrm{~V}$ and speed of $752 \mathrm{rpm}$ at $75 \mathrm{~dB}$ with belt and pulley connection.

\section{Acknowledgments}

We hereby acknowledged Quintas Renewable Energies Solution Limited for allowing this experimentation to be done in their companies and at the same time Professor B. Kareem (Mechanical Engineering Department), Federal University of Technology Akure for supporting this research to come to reality.

\section{Conflicts of Interest}

The authors declare no conflicts of interest regarding the publication of this paper. 


\section{References}

[1] Allan, A.P., Jago, M.B. and Cesar, D.C. (2019) Vibration Analysis of Rotary Machines Using Machine Learning Techniques. European Journal of Engineering Research and Science, 4, 12-16. https://doi.org/10.24018/ejers.2019.4.2.1128

[2] Bently, D.E., Hatch, C.T. and Grissom, B. (2002) Fundamentals of Rotating Machinery Diagnostics. Bently Pressurized Bearing Press.

[3] Vishnu, K.V., Anoop, B.K. and Adarsh, K.S. (2015) Vibration Analysis: A Literature Review. Journal of Electronics and Communication Engineering (IOSR-JECE), 10.

[4] Gunaratne, M. (Ed.) (2006) The Foundation Engineering Handbook. CRC Press. https://doi.org/10.1201/9780203484418

[5] Codulo, C.P., Kitch, W.A. and Yeung, M.R. (2016) Foundation Design: Principles and Practice. 3rd Edition, Pearson, Tokyo.

[6] Teng, W.C. (1992) Foundations Design. 30th Edition, Prentice-Hall, Inc., Englewood Cliff, USA.

[7] Hodgkinson, A. (1986) Foundation Design. 1st Edition, Biddles, Ltd., Guildford and King's Lynn, Great Britain.

[8] Timlinson, M.J. (2001) Foundation Design and Construction. 7th Edition, Pearson Educational, Ltd., England.

[9] Allaire, P.E., Parsell, J.K. and Barrett, L.E. (1981) A Pad Perturbation Method for the Dynamic Coefficients of Tilting-Pad Journal Bearings, Wear, 72, 29-44. https://doi.org/10.1016/0043-1648(81)90281-7

[10] Jayarajan, P. and Kouzer, K.M. (2014) Dynamic Analysis of Turbo-Generator Machine Foundations. Journal of Civil Engineering and Environmental Technology, 1, 30-35.

[11] Fleisher, P.S. and Trombik, P.G. (2008) Turbo-Generator Machine Foundations Subjected to Earthquake Loadings. The 14th World Conference on Earthquake Engineering, 2008.

[12] Fang, M, and Wang, T. (2012) Dynamic Behavior of Turbine Foundation Considering Full Interaction among Facility, Structure and Soil. 15th World Conference on Earthquake Engineering 2012, Lisbon, 24-28 September, 2012.

[13] Prakash, S. and Vijay, K.P. (2006) Foundation for Vibrating Machines. Journal of Structural Engineering, SERC, Special Issue, April-May, 2006.

[14] Bhatia, K.G. (2008) Foundations for Industrial Machines-Handbook for Practicing Engineers. DCAD Publishers. 